\title{
Learning strategies: An answer to our Christian responsibilities towards multicultural education?
}

\author{
C.K. van Wyk \\ Dept. of Mathematics \\ Potchefstroom University for CHE \\ POTCHEFSTROOM
}

\author{
Annette M. van Aardt \\ Dept. of Nutrition and Family Ecology \\ Potchefstroom University for CHE \\ POTCHEFSTROOM
}

\begin{abstract}
Learning strategies: An answer to our Christian responsibilities towards multicultural education?

In a country where development is currently a high priority, effective and efficient learning presents special imperatives for multicultural higher education. One of man's Christian responsibilities is that of education, and in the changing society of the RSA teaching will require a sensitivity to the variation in individual personalities as well as diversity in culture. Students, however, need to realise that they will have to assume a greater responsibility and accountability for their own learning. Knowledge of their own learning and study strategies and application of these can contribute significantly to the accomplishment of optimal learning. An emphasis shift from improved teaching to improved learning has resulted in a depiction of the learner as an active participant in the teaching-learning act. Various instruments for the assessment of learning and study strategies have been developed since the sixties. Two instruments of the past decade that have been tested at the Potchefstroom University since 1989 are discussed and the adoption of the LASSI (Learning and Study Strategies Inventory) is motivated.
\end{abstract}

\section{Introduction}

Diversity, multiculturalism, global awareness, global interdependence, cost-effectiveness, assessment, quality assurance and many more concepts became buzz words at the international congress of the World Association for Educational Research in Israel during July 1993. These issues present special imperatives for higher education and in order to deal with them successfully, accountability for the teaching and learning of students will be expected from universities, technikons, colleges and other higher educational institutions. 
The purpose of this review is to delineate the educator's responsibility towards education from a Christian point of view, to examine possible relationships between student study behaviour and academic achievement reported in the literature, to describe instruments for assessing students' learning in general and to motivate the suitability of one of these instruments for use in multicultural education on South African campuses.

\section{Our Christian responsibility towards education}

In today's world of turmoil, unrest, economic instability and unemployment, is education that important? Is effective and efficient teaching and learning by any means the responsibility of us, the faculty members of a Christian university, and if so, why? A Christian view of creation will elucidate this issue. God commanded man to be fruitful and to have dominion over every living thing that moves upon the earth (Marshall, 1984:21). This is usually referred to as the cultural mandate, and Van der Walt (1992:182) points out that this mandate is part of God's plan of world creation. He also points out that the development of the rich potential of creation can in a sense be seen as a continuation of God's creative acts, provided that the radical difference between Him and man be kept in mind. We are made in the image of God and are called to shape and form the materials of creation. Man in this role can be seen as a manager or steward responsible for shepherding God's world, supplying the needs of others and shaping the development of human life, a view which is shared by Wolters (1985:14).

One of man's responsibilities in God's world is that of education (Romans 12:7) and the authors comply with the vision of Fowler $e t$ al. (1990:1) of a schooling practice that is shaped and directed by the Gospel. Van der Walt (1989:25) describes education as the purposeful effort of the educator to guide the educand, according to specific norms, towards maturity and equipment for life's task. One way of guiding students to enable them to develop with the purpose of becoming competent, is to assist them to reach their full potential by studying in the most effective and efficient way. Many researchers (Pintrich \& Johnson, 1990; Moelwyn-Hughes, 1989; Weinstein \& Mayer, 1986) are of the opinion that students, especially beginner students, need to realise that they will have to assume a greater responsibility and accountability for their own learning.

In a changing society, a new educational strategy will be needed - a strategy which will allow the freedom of variation within communalities. Du Plessis (1993:5) points out that we cannot afford to await the future passively, as repetition of our past will then be inevitable. Our cultural future in South Africa is much richer in alternatives than our past. In the past, our cultural activities tended to be based on only one set of values, namely simplicity, stability, exclusiveness, continuity, clarity, order and manipulativeness. The foundations for a suc- 
cessful multicultural education system should rest on three fundamental perspectives described by Van der Walt (1993:33), namely fundamental equality of all people, acknowledgement of variety among people and their cultures and acknowledgement of the necessity of unity among people.

Fowler et al. (1990:3-5) clearly state that Christian schooling is not marked by conformity to a certain uniform pattern of schooling practice. People who undergo schooling are created in God's image, each one with a unique character and set of gifts, and educators should not pursue an educated 'product' of units shaped alike in one mould, but should strive to develop the unique character and gifts of each individual.

\section{Student study behaviour and academic achievement in a multicultural society}

As the educational scene in South Africa changes, educators will in the near future be facing a tremendous challenge with respect to multicultural education. Good teaching requires a sensitivity to the variation in individual personalities as well as diversity in culture - two aspects that will have to be dealt with in South African classrooms, now and in the future. Western culture differs considerably from traditional African cultures, as is described in detail by Van der Walt (1990: 23-39).

In contrast to the strongly developed sense of communalism in the African culture, individual initiative is encouraged among Westerners, and competition, drive and perseverance are expected of individuals. One way in which to make provision for individual uniqueness and cultural diversity is to guide students to obtain a better understanding of their particular gifts and ways of developing them.

To be able to learn in one's own way, is a gift of God (1 Corinthians 7:7; Romans 12:4-8). The learning characteristics of each learner, therefore, are directed by a wide variety of different strategies in order to store and retrieve information (Weinstein \& Underwood, 1985). Some learners use deductive rather than inductive strategies, some react more positively to certain types of stimuli than to others, while the levels of abstract thinking individuals are capable of, also influence the learning process (Fowler et al., 1990:143). Learning strategies, whether observable or not, are considered worthy objects of scientific investigation (Garner, 1988:63).

Recent studies (Ickes \& Fraas, 1990:30; Pintrich \& Johnson, 1990:83; Karabenick \& Knapp, 1991:221) indicate that many students lack effective learning strategies, and it seems as if the implementation of a learning strategy programme in which learning strategies are assessed and remedial procedures are provided for, 
offers a promising means of improving effective learning and consequently, higher levels of academic achievement.

\section{Foundations of learning strategies research}

In recent years, studies in human learning have reflected a new sense of freedom from classical behaviourism, eclipsing the almost total dependence on the effects of external events on learning (Weinstein, 1988) and emphasis on the improvement of teaching rather than of learning (Dansereau, 1978). Increasing acknowledgement of and interest in the role of man in human behaviour (Palmer \& Goetz, 1988:55), resulted in ushering in the learner as an active participant in the teaching/earning act (Weinstein \& Mayer, 1986). The latter view, coinciding with the growth of cognitive psychology, caused the attention of researchers to shift towards studying the ways in which learners process incoming stimuli (Weinstein \& Underwood, 1985), while recognising the existence and importance of conceptual structures within which incoming facts and principles are embedded and organised (McKeachie et al., 1986:25). Therefore, strategies which serve the integration of mental contents and functions to promote versatility and formation of individuality, and personal identity should be identified (Schmeck, 1988:5), simultaneously providing information on the cognitive characteristics of learners which play an important role in what is being learned (Pintrich, 1988). The complex variations in the ways and facilities by which individuals learn, should finally be taken into account, to the extent that learning can be planned in such a way as to celebrate the diversity with which God has created us (Fowler et al., 1990: 143).

Research on learning strategies is concerned with the apparent influence of learning strategy deficiency on the outcome of learning. Shifts in admission policies, allowing underprepared students into tertiary education, have brought the problem of students lacking certain skills into the open (Weinstein \& Underwood, 1985). Consequently, research was directed towards establishing the relationships between the nature and quality of learning strategies and academic performance (Ickes \& Fraas, 1990; Van Aardt et al., 1994).

The research environment regarding learning strategies neither ignores nor exists in conflict with esteemed psychological constructs of yesteryear. Informationprocessing approaches to intelligence have stressed the dynamic processes involved in intelligence rather than static traits in individuals. Conceptualising personality variables such as motivation in terms of process-oriented, dynamic characteristics of individuals, rather than stable, enduring traits (McKeachie $e t$ al., 1986), also indicate a dynamic interplay between personality and cognition (Palmer \& Goetz, 1988:56; Entwistle, 1988:22; Schmeck, 1988:172). 
Finally, research on learning strategies has reaffirmed the difference between the ways individuals process and think about material to be learned (Pintrich, 1988). The consequence of this is that the identification and modification of learning strategies have been researched vigorously in the past three decades, influenced by a growing understanding of the processes by which people learn (Mayer, 1988:11). There is also evidence that strategies involved in learning can be changed in accordance with situational demands. It is also assumed that the use of different learning strategies can be controlled by the learner (Pintrich \& Johnson, 1990)

\section{Learning strategies}

The term learning strategy refers to the implementation of a sequence of activities (Garner, 1988:64) for accomplishing learning by facilitating the encoding of learning matter in such a way that knowledge integration and retrieval are enhanced (Weinstein, 1988). This definition is in accordance with Mayer's view (1988) that learning strategies are behaviours of a learner that are intended to influence the way in which the learner processes information, using generally deliberate, planned and consciously-engaged activities (Garner, 1988:64). In view of the modern approach to effective learning, effective students are now seen as active information processors, interpreters and synthesizers using a variety of different strategies to select, encode, store and retrieve information. In this process students take more responsibility for their own learning (Weinstein \& MacDonald, 1986). Support strategies like the management of the study environment takes an undeniable place in these strategies.

The need for the classification of learning strategies as influenced by this more modern approach to effective learning, encompassing the entire learning situation, has not led towards a convergence of opinion among researchers. Dansereau $(1978: 3-4 ; 18-25)$ broadly considered primary strategies (operating directly on the text material) and support strategies which should allow the primary strategies to flow efficiently and effectively (e.g. concentration and monitoring). McKeachie et al. (1986) identified the categories intelligence, motivation, personality and cognitive styles. Weinstein and Mayer (1986) proposed three categories of learning strategies, namely cognitive strategies (rehearsal, elaboration and organisation), metacognitive strategies (the awareness of and knowledge about cognition, as well as the control and regulation of cognition) and resource management strategies (a variety of strategies assisting students in managing the environment and the resources available, the strategies having both cognitive and metacognitive elements). Weinstein (1988:292), concerned with reducing performance anxiety, external distractions and procrastination, later included a category of affective strategies to the above list. 
The enthusiasm and vigour with which the research on learning strategies has advanced with leaps and bounds could, however, be tempered by mounting confusion in recent literature concerning the term learning strategy (Derry, 1990), which is reflected by inconsistent definitions of learning strategies (Hulick \& Higginson, 1989). The inevitable outcome of this is the current absence of one organisational scheme that is generally accepted as a way of classifying learning strategies (Weinstein, 1988:292).

\section{Learning strategy assessment: Issues and instruments of recent decades}

The issue of assessing students' learning strategies is especially important in the new picture of learning, in which studying and the forms of autonomous learning and management that comprise it are receiving increased attention. Students engage in a variety of learning activities like lectures, discussions, small group collaborations, laboratory exercises, textbook readings, homework and studying for tests and examinations. In a multicultural society, as in the RSA, it can be assumed that some of the students at university entry level will be underprepared. Being underprepared is not an indicator of students' intellectual abilities, but rather their inadequate environmental and educational experiences. Underprepared students also have weaknesses in study skill strategies (Confer-Owens, 1992). Besides helping students to become more aware of appropriate learning strategies and motivating them to use these strategies, the information generated by assessing instruments can enlighten faculty members about the study skills of their students. This kind of information can in turn be used in teaching (Pintrich \& Johnson, 1990).

Traditional efforts to assess and, if necessary, to change the learning and study habits of students clearly reflect the absence of a sound theory regarding the processes involved in effective learning. Traditional efforts concentrated on ways to improve retention by rote memorisation (Dansereau, 1978:2), the implementation of mechanical aids such as mnemonic devices, including paired-associate learning, serial list learning and free recall learning (Weinstein, 1988:292). The use of questions, the utility of note taking, underlining, outlining and summarisation were also regarded as important aids to enhance recall (Reynolds \& Shirey, 1988:78). The SQ3R programme for more effective learning consisted, in effect, of a sequential five-step application of earlier proposed learning aids, viz. survey, questions, read, recall and review (Dansereau, 1978:7). The popularity of the SQ3R was one of the major reasons for the blossoming of research on learning strategies (Paris, 1988:299). It is unfortunately also apparent that the main objective for introducing students to these programmes was to improve their grades, leaving students with no better knowledge of their own learning activities or of altemative strategies (Dansereau, 1978:7). 
Early self-report inventories which paved the way for means of assessing the learning strategies of individuals are exemplified by the well-known and widelyused Survey of Study Habits and Attitudes, designed by Brown and Holtzman in the sixties (Entwistle, 1988:26). This inventory, containing four subscales, namely work methods, delay avoidance, teacher approval and educational acceptance, was one of the first instruments endeavouring to assess learning strategies related to study organisation, attitudes to courses and to teachers and motivation (Entwistle, 1988:26). Instruments for assessing learning strategies prior to the seventies, however, suffered credibility because of a lack of an underlying theoretical or conceptual framework, containing few items on how students actually learn or process material (Weinstein \& Underwood, 1985:244-245). Most of these inventories used a 'correlational' approach, i.e. trying to find behaviours or activities correlating with successful studying, but which may not be the direct cause of successful learning (Svensson, 1977:233). Selecting items on the basis of how well they distinguished between students with high and low grade-point averages, with IQ and achievement test scores controlled, was also the procedure used (Weinstein \& Underwood, 1985:244) for constructing and validating Brown's Effective Study Test (1964) and Christensen's College Adjustment and Study Skills Inventory (1968).

With the emergence of clear cognitive foundations for effective learning from the sixties onwards, together with the increasing availability of user-friendly statistical techniques such as factor analysis and cluster analysis, instruments to identify learning strategies and assess students' knowledge and use of their learning strategies, became more sophisticated. These more modern instruments, focusing mainly on the college or high school student's study practices, are generally used for a number of purposes, including the prediction of academic performance, counselling students on their study practices and screening or criterion measures for study skills courses (Weinstein \& Underwood, 1985:244). An early example is a study techniques questionnaire which was able to distinguish between above and below average students on grounds of diligence in study habits and an active learning style, the latter referring to building on previous understanding of subject matter or relating new information to material learned in related courses (Goldman \& Warren, 1973). The Inventory of Learning Processes (Schmeck $e t$ al., 1977) is another instrument developed expressly to measure kinds of information-processing activities students use while trying to learn academic material. This Inventory contains four subscales, namely elaborative processing (the approach by which the information to be learned is related to the learner's existing knowledge in the same or related fields); synthesis-analysis (measuring the learner's use of organisational strategies); fact retention (examining the learner's techniques for retaining specific facts and details) and methodical study methods (mainly assessing learners' use of traditional study techniques on a regular basis) (Schmeck, 1988:176-178). 
Learning strategies: Responsibilities towards multicultural education

In Entwistle's Approaches to Studying Inventory (Entwistle, 1988) the main idea of orientation to studying emerges, focusing on the consistency of approach and, to a lesser degree, the existence of both approach and motivation. The four subscales, corresponding to factors extracted by means of factor analysis, comprise meaning orientation, reproducing orientation, and less distinctly, achieving orientation and non-academic orientation, with the first three factors having distinctive motivational correlates (Entwistle, 1988). A combination of items of Schmeck's and Entwistle's inventories were administered to students in both Britain and the USA in the first half of the previous decade with the factor analysis of the responses resulting in a factor structure showing a very clear pattern linking the two inventories (Entwistle, 1988).

The emergence of several inventories in the previous decade to assess the strategies concerned with effective learning was largely the result of researchers' efforts to probe into the existence of those strategies they believed to be associated with effective learning, to group mutual supportive strategies into categories, and to correlate the levels of learners' implementation of strategies with their learning outcomes. Comparing the results of different inventories, like Entwistle's and Schmeck's, administered to the same group of students, should have been the beginning of efforts to curb a possible growing divergence of opinion on types and the nature of learning strategies.

Two instruments recently developed in the USA for assessing learning strategies, namely the LASSI (Learning and Study Strategies Inventory) and the MSLQ (Motivated Strategies for Learning Questionnaire) have been in use at the Potchefstroom University for Christian Higher Education since 1989. A brief discussion of these instruments will reveal that both are based on general cognitive models of the student as an active information processor who can influence the learning process.

\subsection{The Learning and Study Strategies Inventory (LASSI)}

After having identified several problems with instruments mentioned earlier in this article, Weinstein and her colleagues set out to develop a new instrument with a major goal to assist educators and trainers in diagnosing strengths and weaknesses in students' learning and study strategies in order to provide individualised remedial training. The design and development of the LASSI are extensively described by Weinstein et al. (1988:28-39).

The LASSI contains 77 items (i.e. statements regarding learning and study strategies), takes approximately twenty minutes to administer and can be self-scored by the student for immediate feedback. Of the ten scales of the LASSI listed in Table 1, five deal with motivation and self-management and five with cognitive strategies 


\subsection{The Motivated Strategies for Learning Questionnaire (MSLQ)}

The MSLQ and LASSI are highly similar instruments, differing mainly in the stronger emphasis on motivation occurring in the MSLQ. The MSLQ was developed by a team of researchers participating in the Program on Learning and Teaching at the federally funded National Center for Research to Improve Postsecondary Teaching and Leaning (NCRIPTAL) at the University of Michigan, Ann Arbor, under the leadership of Pintrich (Pintrich et al., 1991:4)

The 1991 version of the MSLQ consists essentially of two sections, namely a motivation section and a learning strategies section. The motivation section contains 31 items which assess students' goals and value beliefs for a course, their beliefs about their skill to succeed in a course and their anxiety regarding tests in a course. The learning strategy section consists of 31 items regarding students' use of different cognitive and metacognitive strategies. The last section contains 19 items concerning student management of different resources like management of time and study environment, effort regulation, peer learning and help seeking.

The reliability and validity of the 81-item MSLQ were determined, resulting in Cronbach's alpha coefficients ranging from 0,52 to 0,93 , while confirmatory factor analysis indicated a reasonable factor validity.

\subsection{Learning strategy assessment in the RSA}

At the time when researchers in the field of learning and instruction at the Potchefstroom University for CHE became interested in learning strategies, the MSLQ was still in the developmental stage, while the LASSI had by then been finalised and published. The authors consequently decided to adopt the LASSI for assessing the learning and study strategies of students in the RSA. Research in this regard has been done by the authors for the past five years. For three consecutive years percentile tables of the responses of the total first-year student groups were constructed. A comprehensive norm table could eventually be created, based on the responses of the total group of first-year students for the three consecutive years. The reliability of the LASSI for South African students (Table 1) was satisfactory to high, with alpha coefficients ranging from 0,65 to 0,84 , which did not differ drastically from those reported for USA students. The validity of the LASSI for South African students was assessed by exploratory as well as by confirmatory factor analysis, which indicated a satisfactory construct validity. The confirmatory factor analysis (Table 2) showed that, with the exception of two LASSI fields, only one factor which was responsible for between $38 \%$ and $49 \%$ of the total variance, was extracted in each field. Even the two constructs which were extracted in each of the two remaining fields explained substantial portions of the total variance. The comprehensive study of investigating 
the suitability of the LASSI for use with South African students is described by Van Aardt et al. (1994).

A practical way of utilising the LASSI-scores of students for their own benefit was also devised by the authors. A computer programme was used to plot each student's scores in the ten fields against the class average scores and the LASSI norms. Profiles help students to locate areas where learning and study strategies may be deficient and for which remediation is necessary. These profiles are quick and easy to produce and can be printed out on request.

From research done in various countries, including own research, it can be concluded that the LASSI is a highly appropriate and sound instrument to determine the learning and study strategies and approach of students.

\section{Opportunities for integrating learning strategies in multicultural education}

Motivational scales (attitude, motivation and anxiety) respectively reflect students' general interest and goals for university, their willingness to accept responsibility for their studies and the extent to which they worry about examinations and doing well in them. Recent experiences at this university revealed an intense desire among students of all cultural groups to acquire tertiary education - a desire which calls for assessing and directing the motivational behaviour of students. Motivational fields are of importance for identifying students who are inclined to attribute underachievement to external factors, supposedly beyond their control.

Attitude scales measure students' general attitudes and motivation for succeeding at university and performing the tasks related to success. Students who score low on this measure need to work on higher level goal setting and reassess how university fits into their future. Students' scores on motivation measure the degree to which they accept responsibility for performing the specific tasks related to university success. Low scores indicate a need to work on goal setting, perhaps at the more global levels assessed on the attitude scale, but certainly at the more specific level of individual tasks and assignments. Accepting more responsibility for studying and achievement outcomes requires that students learn to attribute much of what happens to them at university to their own efforts rather than to outside forces such as luck or poor teachers, or to uncontrollable forces such as innate ability. Anxiety scales measure how tense or anxious students are when approaching academic tasks. High anxiety calls for the learning of techniques for coping with anxiety and reducing worry so that students can focus on the task and not on their anxiety. 
C.K. van Wyk \& Annette M. van Aardt

Cognitive scales (information processing, selecting main ideas, study aids, selftesting and test strategies) concentrate on the thinking processes of students with regard to active involvement in integrating and connecting course material to prior knowledge, assuming that passive strategies like rehearsing, copying notes and underlining are less likely to be beneficial for meaningful learning. Exposure to cognitive developmental activities has not been pursued with equal enthusiasm and effect among different cultural groups in the RSA (Van Aardt \& Du Plessis, 1988).

An information processing scale measures how well students can create imaginal and verbal elaborations and organisations to foster understanding and recall. Students who apply this strategy insufficiently, need to learn methods enabling them to help add meaning and organisation to what they are trying to learn. Selecting main ideas scales address students' skills at selecting important information to concentrate on for further study in either classroom lecture or autonomous learning situations. The ability to identify important information will help students to focus their attention and information processing strategies on appropriate material.

Study aids items examine the degree to which students use or create study aids that support and increase meaningful learning and retention. It may be necessary for low scorers in this area to learn more about the types of study aids provided in educational materials and classes and how they can create their own aids. A selftesting scale focuses on students' awareness of the importance of self testing and reviewing and the degree to which they use these methods. The importance of self-testing and the need to learn specific methods to review academic material and to monitor their comprehension must be emphasized among students who do not utilise this strategy satisfactorily.

Another cognitive scale, test strategies, evaluates students' use of test-taking and test preparation strategies. Students may need to learn more about how to prepare for tests, how to initiate a plan of attack for taking a test, the characteristics of different types of tests and test items, and how to reason through to an answer if they do not score well on this measure.

Two self-management scales (time management and concentration) reflect students' skills at directing and controlling their study behaviour. Students' scores on the time management scale measure the degree to which they create and use schedules. Students who lack this competency may need to learn how to create a schedule and how to deal with distractions, competing goals and procrastination factors that might not have been addressed incisively among all cultural groups in this country. 
Items on concentration measure students' abilities to concentrate and direct their attention to university-related tasks, including study activities. Students who score high on this measure are effective at focusing their attention and maintaining a high level of concentration, while those who score low on this measure are less successful at focusing their attention on the task at hand by eliminating interfering thoughts, emotions, feelings and situations.

\section{Closing remarks}

Knowledge of learning and study strategies and their application may assist students to accomplish optimal learning success. Educators can serve the students by helping them to assess their learning strategies, the nature and application of which may differ considerably among students. Only when optimal studying and learning take place, can the process of guiding and equipping students of all cultural groups to become competent learners proceed satisfactorily. In this way educators can address their Christian responsibilities towards education which, however, do not end here, as Van der Walt (1989:29) points out that the highest ideal should be to teach students to submit to God and his laws willingly. The educator should thus be careful not to reduce this optimal learning situation to mere ways and means of memorising facts, but to guide people towards maturity and assist them in equipping themselves for their life's task in such a way that they will simultaneously be equipped for discipleship in God's service. That the Christian responsibility of the South African educator in this respect is unique and challenging in a changing and multicultural South Africa cannot be debated.

\section{Table 1}

Reliability of the LASSI by means of $\alpha$-coefficients

\begin{tabular}{|l|l|l|}
\hline LASSI-fields & $\begin{array}{l}\alpha \text {-coefficients for PU for } \\
\text { CHE students }\end{array}$ & $\begin{array}{l}\alpha \text {-coeflicients for USA } \\
\text { students }\end{array}$ \\
\hline Attitude & 0.65 & 0.72 \\
\hline Motivation & 0.76 & 0.81 \\
\hline Time management & 0.78 & 0.86 \\
\hline Anxiety & 0.81 & 0.81 \\
\hline Concentration & 0.84 & 0.84 \\
\hline Information processing & 0.80 & 0.83 \\
\hline Selecting main ideas & 0.74 & 0.74 \\
\hline Study aids & 0.70 & 0.68 \\
\hline
\end{tabular}




\begin{tabular}{|l|l|l|}
\hline LASSI-fields & $\begin{array}{l}\alpha \text {-coefficients for PU for } \\
\text { CHE students }\end{array}$ & $\begin{array}{l}\alpha \text {-coefficients for USA } \\
\text { students }\end{array}$ \\
\hline Self-testing & 0.77 & 0.75 \\
\hline Test strategies & 0.78 & 0.83 \\
\hline
\end{tabular}

This table was published in Van Aardt et al. (1994:230)

\section{Table 2}

Construct validity of the different LASSI-fields for students at the PU for CHE by means of confirmative factor analysis

\begin{tabular}{|l|l|l|l|}
\hline LASSI-fields & $\begin{array}{l}\text { Factor 1 } \\
\text { \% variance } \\
\text { declared }\end{array}$ & $\begin{array}{l}\text { Factor 2 } \\
\text { \% variance } \\
\text { declared }\end{array}$ & $\begin{array}{l}\text { Total \% variance } \\
\text { declared by 1 or 2 } \\
\text { factors }\end{array}$ \\
\hline Attitude & 27.98 & 16.72 & 44.70 \\
\hline Motivation & 38.39 & - & 38.39 \\
\hline Time management & 43.03 & - & 43.03 \\
\hline Anxiety & 44.42 & - & 44.42 \\
\hline Concentration & 49.39 & - & 49.39 \\
\hline Information processing & 43.33 & - & 43.33 \\
\hline Selecting main ideas & 49.47 & - & 49.47 \\
\hline Study aids & 34.12 & - & 34.12 \\
\hline Self-testing & 29.27 & 23.15 & 52.42 \\
\hline Test strategies & 39.88 & - & 39.88 \\
\hline
\end{tabular}

*After an orthogonal rotation by the varimax method

This table was published in Van Aardt et al. (1994:231)

\section{Bibliography}

CONFER-OWENS, V.A. 1992. Effectiveness of Suggestive-Accelerative Learning Techniques in Teaching Underprepared College Freshmen. Paper presented at the Mid-South Educational Research Association, Knoxville. pp. 1-15.

DANSEREAU, D. 1978. The Development of a Learning Strategies Curriculum. (In O'Neil, H.F. ed. Learning Strategies. New York: Academic Press. pp. 1-29.)

DERRY, S.J. 1990. Remediating Academic Difficulties through Strategy Training: The Acquisition of Useful Knowledge. Remedial and Special Education, 11(6):19-31 
DU PLESSIS, P.G.W. 1993. Kultuursake in 'n nuwe Suid-Afrika. Academic Standard, 2(1): 5 .

ENTWISTLE, N. 1988. Motivational Factors in Students' Approaches to Learning. (In Schmeck, R.R ed Learning Strategies and Learning Styles. New York: Plenum Press. pp. 21-51.)

FOWLER, S., VAN BRUMMELEN, H.W. \& VAN DYK, J. 1990. Christian Schooling Education for Freedom. Potchefstroom : PU for CHE.

GARNER, R. 1988. Verbal-Report Data on Cognitive and Metacognitive Strategies. (In Weinstein, C.E., Goetz, E.T. \& Alexander, P.A. Learning and Study Strategies - Issues in Assessment, Instruction and Evaluation. San Diego : Academic Press. pp. 63-76.)

GOLDMAN, R.D. \& WARREN, R. 1973. Discriminant Analysis of Study Strategies Connected with College Grade Success in Different Major Fields. Journal of Educational Measurement, 10(1):39-47.

HULICK, C. \& HIGGINSON, B. 1989. The Use of Learning and Study Strategies by College Freshmen. Paper presented at the Mid-South Educational Research Association, Little Rock. pp. 1-18.

ICKES, C. \& FRAAS, J.W. 1990. Study Skills Differences among High-Risk College Freshmen. Paper presented at the Annual Meeting of the Mid-Western Educational Research Association in Chicago, Oct 17-20. pp. 1-29.

KARABENICK, S.A \& KNAPP, J.R. 1991. Relationship of Academic Help Seeking to the Use of Learning Strategies and Other Instrumental Achievement Behavior in College Students. Journal of Educational Psychology, 83(2):221-230.

MARSHALL, P. 1984. Thine Is the Kingdom. Toronto : Marshalls.

McKEACHIE, W.J., PINTRICH, P.R., LIN, Y-G. \& SMITH, D.A.F. 1986. Teaching and Learning in the College Classroom - a Review of the Research Literature. Ann Arbor : The University of Michigan, Technical Report No. 86-B-001.1

MAYER, R.E. 1988. Leaming Strategies: An Overview. (In Weinstein, C.E., Goetz, E.T. \& Alexander, P.A. Learning and Study Strategies - Issues in Assessment, Instruction, and Evaluation. San Diego : Academic Press. pp. 11-22.)

MOELWYN-HUGHES, T. 1989. Approaches to Improving Student Learning. How Can We Improve the Learning Process? Academic Staff Development Centre. Johannesburg University of the Witwatersrand.

PALMER, D.J. \& GOETZ, E.T. 1988. Selection and Use of Study Strategies: The Role of the Studier's Beliefs about Self and Strategies. (In Weinstein, C.E., Goetz, E.T. \& Alexander, P.A. Learning and Study Strategies - Issues in Assessment, Instruction, and Evaluation. San Diego : Academic Press. pp. 41-61.)

PARIS, S.G. 1988. Models and Metaphors of Learning Strategies. (In Weinstein, C.E., Goetz, E.T. \& Alexander, P.A. Learning and Study Strategies - Issues in Assessment, Instruction, and Evaluation. San Diego : Academic Press. pp. 299-321.)

PINTRICH, P.R. 1988. Student Learning and College Teaching. New Directions for Teaching and Learning, No. 33. San Francisco : Jossey-Bass. pp. 71-86

PINTRICH, P.R. \& JOHNSON, G.R. 1990. Assessing and Improving Students' Learning Strategies. New Directions for Teaching and Leaming, No. 42. San Francisco : JosseyBass. pp. 83-92.

PINTRICH, P.R., SMITH, D.A.F., GARCIA, T. \& McKEACHIE, W.J. 1991. A Manual for the Use of the Motivated Strategies for Learning Questionnaire (MSLQ). Ann Arbor.

REYNOLDS, R.E. \& SHIREY, L.L. 1988. The Role of Attention in Studying and Leaming (In Weinstein, C.E., Goetz, E.T. \& Alexander, P.A. Learning and Study Strategies Issues in Assessment, Instruction, and Evaluation. San Diego : Academic Press. pp. 77100.) 
SCHMECK, R.R., RIBICH, F. \& RAMANAIAH, N. 1977. Development of a Self-Report Inventory for Assessing Individual Differences in Learning Processes. Applied Psychological Measurement, 1(3):413-431

SCHMECK, R.R. 1988. Individual Differences and Learning Strategies. (In Weinstein, C.E. Goetz, E.T. \& Alexander, P.A. Learning and Study Strategies - Issues in Assessment, Instruction and Evaluation. San Diego : Academic Press pp. 171-191.)

SVENSSON, L. 1977. On Qualitative Differences in Learning: III - Study Skill and Learning. British Journal of Educational Psychology, 47:233-243.

VAN AARDT, A.M. \& DU PLESSIS, S.J.P. 1988. Cognitive Development among Students of Textile Science at University. South African Journal of Science, 84(5):442-444

VAN AARDT, A.M., VAN WYK, C.K. \& STEYN, H.S. 1994. The LASSI for Assessment of Students' Learning and Study Strategies in the RSA. South African Journal of Higher Fducation, 8(1):226-232.

VAN DER WALT, B.J. 1989. Potchefstroom, Afrika roep jou! (In Instituut vir Reformatoriese Studie. Visie en missie - IRS 25 jaar. Potchefstroom: PU vir CHO. pp. 1370.) (Reeks F3: Versamelwerke Nommer 35.)

VAN DER WALT, B.J. 1990. Om mens te wees: Gawe en opgawe - onderweg na 'n Christelike mensvisie vir Afrika. Potchefstroom : PU vir $\mathrm{CHO}$.

VAN DER WALT, B.J. 1992. Venster op die werklikheid - 'n reformatoriese lewensvisiefilosofiewetenskap. Potchefstroom : $\mathrm{PU}$ vir $\mathrm{CHO}$

VAN DER WALT, B.J. 1993. Op soek na gemeenskaplike kulturele waardes vir 'n toekomstige Suid-Afrika: 'n Voorlopige verkenning. Reeks F1: IRS-studiestuk No. 309. Potchefstroom: Instituut vir Reformatoriese Studie. 36p.

WEINSTEIN, C.E. 1988. Assessment and Training of Student Learning Strategies. (In Schmeck, R.R. ed. Learning Strategies and Learning Styles. New York : Plenum Press pp. 291-316.)

WEINSTEIN, C.E. \& MAYER, R.E. 1986. The Teaching of Learning Strategies. (In Wittrock, M. ed. Handbook of Research on Teaching. New York : Macmillan. pp 315-327.)

WEINSTEIN, C.E. \& MACDONALD, J.D. 1986. Why Does a School Psychologist Need to Know about Learning Strategies? Journal of School Psychology, 24:1-9

WEINSTEIN, C.E. \& UNDERWOOD, V.L. 1985. Learning Strategies: The How of Learning. (In Segal, J.W., Chipman, S.F. \& Glaser, R. eds. Thinking and Learning Skills. Vol. 1: Relating Instruction to Research. Hillsdale : Lawrence Erlbaum. pp. 241-258.)

WEINSTEIN, C.E., ZIMMERMAN, S.A. \& PALMER, D.R. 1988. Assessing Learning Strategies: The Design and Development of the LASSI. (In Weinstein, C.E., Goetz, E.T. \& Alexander, P.A. Learning and Study Strategies - Issues in Assessment, Instruction, and Evaluation. San Diego : Academic Press. pp. 25-40.)

WOLTERS, A.M. 1985. Creation Regained - Biblical Basics for a Reformational Worldview. Grand Rapids : William E. Eerdmans Publishing Company. 
